\title{
METHODS OF SAMPLING AIRBORNE FUNGI IN WORKING ENVIRONMENTS OF WASTE TREATMENT FACILITIES
}

\section{KRISTÝNA ČERNÁ ${ }^{1}$, ZDEŇKA WITTLINGEROVÁ ${ }^{1}$, MAGDALÉNA ZIMOVÁ, and ZDENĚK JANOVSKÝ²,3}

\author{
${ }^{1}$ Czech University of Life Sciences Prague, Prague, Czech Republic \\ Faculty of Environmental Sciences, Department of Applied Ecology \\ ${ }^{2}$ Charles University in Prague, Prague, Czech Republic \\ Faculty of Science, Department of Botany \\ ${ }^{3}$ Academy of Sciences of the Czech Republic, Průhonice, Czech Republic \\ Institute of Botany
}

\begin{abstract}
Objectives: The objective of the present study was to evaluate and compare the efficiency of a filter based sampling method and a high volume sampling method for sampling airborne culturable fungi present in waste sorting facilities. Material and Methods: Membrane filters method was compared with surface air system method. The selected sampling methods were modified and tested in 2 plastic waste sorting facilities. Results: The total number of colony-forming units (CFU) $/ \mathrm{m}^{3}$ of airborne fungi was dependent on the type of sampling device, on the time of sampling, which was carried out every hour from the beginning of the work shift, and on the type of cultivation medium $(\mathrm{p}<0.001)$. Detected concentrations of airborne fungi ranged $2 \times 10^{2}-1.7 \times 10^{6} \mathrm{CFU} / \mathrm{m}^{3}$ when using the membrane filters (MF) method, and $3 \times 10^{2}-6.4 \times 10^{4} \mathrm{CFU} / \mathrm{m}^{3}$ when using the surface air system (SAS) method. Conclusions: Both methods showed comparable sensitivity to the fluctuations of the concentrations of airborne fungi during the work shifts. The SAS method is adequate for a fast indicative determination of concentration of airborne fungi. The MF method is suitable for thorough assessment of working environment contamination by airborne fungi. Therefore we recommend the MF method for the implementation of a uniform standard methodology of airborne fungi sampling in working environments of waste treatment facilities.
\end{abstract}

Key words:

Airborne fungi, Waste sorting facility, Filter based bioaerosol sampling, Surface air system method, Working environment, Plastics

\section{INTRODUCTION}

In recent years, municipal solid waste production has been growing worldwide. Because of its excessive production, there has been an increasing pressure on recycling, especially of plastic waste. Municipal solid waste from collecting containers is accumulated and subsequently handled in waste sorting facilities.

Municipal solid waste is usually contaminated by many microorganisms [1]. Fungi constitute an essential part of the solid waste. They are capable of overgrowing

Grant No. 4222013123163 entitled "Methods for detection of microscopic fungi in working environment of waste treatment facilities" supported by Grant Agency of the Faculty of Environmental Sciences, Czech University of Life Sciences Prague. Project manager: Kristýna Černá, M.Sc.

Received: January 12, 2015. Accepted: July 8, 2015.

Corresponding author: K. Cerná, Czech University of Life Sciences Prague, Faculty of Environmental Sciences, Department of Applied Ecology, Kamýcká 129, 16521 Prague 6 - Suchdol, Czech Republic (e-mail: cernakristyna@fzp.czu.cz). 
the organic residues adhering to the waste and can produce a large number of reproductive particles. During the waste handling, the particles of fungi can be released into the working environment and become a part of bioaerosol [2]. The facility employees may be exposed to the bioaerosol primarily through inhalation [3]. High concentration of the bioaerosol in the working environment may cause a number of health problems [4,5].

Studies dealing with the problems of contamination of working environments in waste treatment facilities show that the facilities are environments with increased concentrations of airborne fungi. The concentrations may vary within a wide range depending on the sampling site, sampling method and processing of samples: $7 \times 10^{2}-7.2 \times 10^{3}$ colonyforming units $(\mathrm{CFU}) / \mathrm{m}^{3}[3], 4.7 \times 10^{2}-2.9 \times 10^{5} \mathrm{CFU} / \mathrm{m}^{3}[6]$, $2.7 \times 10^{2}-1.6 \times 10^{5} \mathrm{CFU} / \mathrm{m}^{3}$ [7], $0-2.2 \times 10^{5} \mathrm{CFU} / \mathrm{m}^{3}$ [8], $0.9 \times 10^{3}-2.3 \times 10^{5} \mathrm{CFU} / \mathrm{m}^{3}$ [9], $0.3 \times 10^{3}-1.3 \times 10^{5} \mathrm{CFU} / \mathrm{m}^{3}$ [10], $1.3 \times 10^{2}-7.3 \times 10^{4} \mathrm{CFU} / \mathrm{m}^{3}$ [11]. The most commonly used sampling methods of airborne fungi in working environments of waste treatment facilities utilize the following sampling devices: Andersen sampler [3,6-8,12] and filter holder with a flow pump [2,6,8-10].

Although the European standards for measuring bioaerosol have been already established (BS-EN 13098:2001 [13], BS-EN 14042:2003 [14]), a uniform methodology for monitoring and evaluating airborne fungi in working environments of waste treatment facilities has not been yet implemented. In most European countries, binding legal limits have not been established either. The most important task in the establishment of this methodology is to determine a suitable sampling method.

The sampling method to be used for the intended uniform methodology should meet the following criteria: the sampling method must respond to the characteristics of the sorting process (e.g., the workload of the sorting line, the quality of the waste) sensitively enough; the results of measurement must be consistent and repeatable, i.e., the sampling method must be repeatable in the detection of differences (due to different technology of sorting process) between various waste treatment facilities. Finally, the sampling method must meet the criterion of low operation costs.

In this study, we used 2 methods of airborne fungi sampling, the surface air system (SAS) method and the membrane filters (MF) method, which could meet the criteria specified above.

The SAS method uses a portable (battery-powered) high flow sampler. The advantages of portable microbial samplers include their light weight, ease of use, and high sampling flow rates without the need for post-collection processing [15]. The portable SAS sampler is able to enumerate airborne microorganisms with the relative overall efficiency of 0.7 ; however, this relative overall efficiency was determined at a relatively low concentration of cultivable airborne microorganisms [16]. Moreover, the efficiency of any air sampler will vary depending on the device used and the nature of the sampled aerosol [15,17]. The SAS method was used for sampling of airborne fungi in many studies [e.g., 18,19].

The MF method is considered to be suitable for using a personal sampler for collection in the breathing zone [20]. The trapping efficiency of membrane filters may vary between 62-99\% [21]. However, bioefficiency of filter samplers depends on the microbial species, type of membrane filter, sampling time and relative humidity [21,22]. The MF sampling method is more accurate in highly contaminated environments [11].

Many types of cultivation media are used for detecting of airborne fungi in working environments of waste treatment facilities, most commonly the MEA (malt extract agar) $[6-8,10,11]$, SDA (Sabouraud dextrose agar) $[2,3]$ or DRBC (dichloran rose-Bengal chloramphenicol) [8]. Cultivation medium YGC (yeast extract glucose chloramphenicol) was used for the determination of airborne fungi in another indoor environment [23]. In this study, we directly compare the properties of these 4 media in terms of their utility for cultivation of airborne fungi. 
The aim of this study is to compare the results of the detection of airborne fungi by the SAS method with the results of the detection by the MF method. Based on the comparison of the results, the best method for the implementation of a uniform standard methodology for sampling and processing of samples of airborne fungi in the working environment of waste treatment facilities has been chosen. The comparison of the 2 methods was carried out in 2 waste sorting facilities during 3 different seasons and at various times of work shifts.

\section{MATERIAL AND METHODS}

\section{Sampling procedure}

The study was conducted in 2 plastic waste sorting facilities in the Czech Republic. The analysis of the working environment was carried out in both facilities. Based on the analysis, a sampling place with the highest expected exposure of the employees to bioaerosol and dust was selected. The sampling place was next to the conveyor belt where the employees sort plastic waste. Samples were collected about $1.5 \mathrm{~m}$ above the ground.

In both facilities, the samples were collected in 2013 and 2014 (October 2013, January 2014, May 2014). During each sampling season, 10 measurements were performed at hourly intervals within 1 work shift, the 1st before the beginning of the work shift and the last one hour after the end of the work shift. The samples of airborne fungi obtained by the SAS and MF methods were cultivated on Petri dishes containing 4 different types of cultivation media, with 6 repetitions of each medium. At each sampling time (i.e., each hour), the temperature and relative air humidity were recorded (see Table 1 for descriptive statistics of the ambient conditions during measurements).

\section{Sampling devices}

Two sampling devices were selected for the sampling of airborne fungi. Single head impaction air sampler Sampl'air Lite (AES Laboratoire Inc., France) which is a part of the SAS method, and a 37-mm Filter Holder (BGI Inc., USA) connected with a portable constant-flow Leland Legacy Sample Pump (SKC Ltd., UK), which is a part of the MF method.

\section{Impaction air sampler}

Air samples were collected onto Petri dishes (90 mm), each containing $25 \mathrm{ml}$ of cultivation medium (see below)

Table 1. Descriptive statistics of the ambient conditions during the measurements

\begin{tabular}{lrrrr}
\hline \multirow{2}{*}{ Season and sorting facility } & \multicolumn{3}{c}{$\begin{array}{c}\text { Temperature } \\
{\left[{ }^{\circ} \mathrm{C}\right]}\end{array}$} & Relative air humidity \\
{$[\%]$}
\end{tabular}

M - mean; SE - standard error. 
placed in the head of the sampling device. The sampler was set at the lowest adjustable flow rate of $100 \mathrm{l} / \mathrm{min}$ (impaction speed of $3 \mathrm{~m} / \mathrm{s}$ ) and the shortest sampling period of $30 \mathrm{~s}$. The amount of air sampled was 501 . After the sampling, Petri dishes were incubated at $25 \pm 1^{\circ} \mathrm{C}$ for $72 \mathrm{~h}$. After incubation, colonies were counted and fungal counts were recalculated as the number of colony-forming units $(\mathrm{CFU}) / \mathrm{m}^{3}$.

\section{Filter holder with a flow pump}

Pre-dried nitrocellulose membrane filters PRAGOPOR 4 (Pragochema, Czech Republic) with the pore size of $0.85 \mu \mathrm{m}$ and the diameter of $35 \mathrm{~mm}$ were placed and sealed in a pre-sterilized filter holder. The filter holder was connected by rubber tubing to the flow pump calibrated to ensure the flow rate of $5 \mathrm{l} / \mathrm{min}$. The amounts of air sampled were 1201 [24] thus, the sampling period per 1 sample was $24 \mathrm{~min}$. After the sampling period, the filter was placed into the sterile airtight polypropylene container, closed and brought to the laboratory for analysis. The extraction of the fungi was performed as follows: $10 \mathrm{ml}$ of sterile distilled water containing $0.05 \mathrm{ml}$ of Tween 80 was added to the filter into the container. The closed container was being subsequently shaken for $15 \mathrm{~min}$ using a shaker. After the extraction, $0.2 \mathrm{ml}$ of fluid was sucked off with a glass pipette and plated out on the cultivation medium in Petri dishes. After incubation, the dishes were evaluated by the procedure identical to that applied in the SAS method.

The temperature and air humidity were determined using a Testo 175 H1 Data Logger (Testo AG, Germany).

\section{Cultivation media}

Four types of cultivation media with added antibiotics were used for the collection of airborne fungi: malt extract agar (Oxoid Ltd., UK) with the addition $100 \mathrm{mg} / \mathrm{l}$ of chloramphenicol supplement (Oxoid Ltd., UK); Sabouraud dextrose agar (Oxoid Ltd., UK) with the addition $100 \mathrm{mg} / \mathrm{l}$ of chloramphenicol supplement (Oxoid Ltd., UK); DRBC agar base (Oxoid Ltd., UK) with the addition $100 \mathrm{mg} / \mathrm{l}$ of chloramphenicol supplement (Oxoid Ltd., UK); and YGC-medium ready-poured plate (Oxoid Ltd., UK). The cultivation media MEA, DRBC and SDA were prepared according to the manufacturer's instructions.

\section{Statistical analysis}

The data were analyzed by means of hierarchical ANOVA due to the split-plot structure of the dataset with 6 levels (see Crawley (2007) [25] or Scheiner and Gurevitch (1993) [26] for more detailed discussion of similar designs). The regression diagnostic plots from preliminary analysis suggested violation of the assumption of homogeneity of variance. Taking the logarithms of the response variable (abundance of CFU of airborne fungi) improved the model so that it satisfied the assumption. The tested predictors were: waste sorting facility, sampling device, sampling time, cultivation medium and all their interactions. Season of the year delimited blocks in the analysis (i.e., the highest hierarchical level of variance). All computations were performed using R 3.0.1 ( $\mathrm{R}$ Core Development Team) statistical environment (base installation) [27].

\section{RESULTS}

In total, 2880 samples were collected. The detected concentrations of airborne fungi were dependent on the type of sampling device, on the time of sampling, which was carried out every hour from the beginning of the work shift, and on the type of cultivation medium (all $p<0.001$ ) (Table 2).

Large proportion of variability in the detected concentrations of airborne fungi was explained by variability between the sampling devices (39.9\% of the total variability) and variability among the times of measurements (38\% of the total variability) (Table 3 ).

The particular differences in descriptive statistics between the levels of predictors are listed in Table 4. 
Table 2. Hierarchical ANOVA of log-number of colony-forming units (CFU) of airborne fungi reported for individual split-plot levels

\begin{tabular}{|c|c|c|c|c|}
\hline Predictor & df & $\begin{array}{c}\text { Explained variation }^{\mathrm{a}} \\
{[\%]}\end{array}$ & Sum of squares & $\mathrm{p}$ \\
\hline \multicolumn{5}{|l|}{ Variation among seasons } \\
\hline residual variation & 2 & 100.0 & 913.2 & \\
\hline \multicolumn{5}{|l|}{ Variation among factories within season } \\
\hline factory identity & 1 & 42.6 & 219.9 & n.s. \\
\hline residual variation & 2 & 57.4 & 295.9 & \\
\hline \multicolumn{5}{|l|}{$\begin{array}{l}\text { Variation among samplers within factory } \\
\text { and season }\end{array}$} \\
\hline sampler type & 1 & 96.1 & 2735.3 & $<0.001$ \\
\hline factory $\times$ sampler & 1 & 0.0 & 0.2 & n.s. \\
\hline residual variation & 4 & 3.9 & 112.1 & \\
\hline \multicolumn{5}{|l|}{$\begin{array}{l}\text { Variation among hours within sampler } \\
\text { type, factory and season }\end{array}$} \\
\hline hour of sampling & 9 & 36.0 & 978.3 & $<0.001$ \\
\hline factory $\times$ hour & 9 & 8.0 & 217.7 & n.s. \\
\hline sampler $\times$ hour & 9 & 2.4 & 65.2 & n.s. \\
\hline factory $\times$ sampler $\times$ hour & 9 & 2.5 & 66.7 & n.s. \\
\hline residual variation & 72 & 51.1 & 1389.1 & \\
\hline \multicolumn{5}{|l|}{$\begin{array}{l}\text { Variation among media within hour, } \\
\text { sampler type, factory and season }\end{array}$} \\
\hline medium & 3 & 21.9 & 20.1 & $<0.001$ \\
\hline factory $\times$ medium & 3 & 1.6 & 1.5 & n.s. \\
\hline sampler $\times$ medium & 3 & 1.1 & 1.0 & n.s. \\
\hline hour $\times$ medium & 27 & 5.4 & 4.9 & n.s. \\
\hline factory $\times$ sampler $\times$ medium & 3 & 0.7 & 0.7 & n.s. \\
\hline factory $\times$ hour $\times$ medium & 27 & 5.8 & 5.3 & n.s. \\
\hline sampler $\times$ hour $\times$ medium & 27 & 5.0 & 4.6 & n.s. \\
\hline factory $\times$ sampler $\times$ hour $\times$ medium & 27 & 4.1 & 3.8 & n.s. \\
\hline residual variation & 240 & 54.4 & 49.9 & \\
\hline \multicolumn{5}{|l|}{$\begin{array}{l}\text { Variation among dishes within medium, } \\
\text { hour, sampler type, factory and season }\end{array}$} \\
\hline residual variation & 2400 & 100.0 & 58.2 & \\
\hline
\end{tabular}

df - degrees of freedom; n.s. - not statistically significant.

${ }^{a}$ Refers to variation within the given hierarchical level. 
Table 3. Proportions of total variation in response (log-number of colony-forming units (CFU) of airborne fungi) explained by each hierarchical level

Level of variation
Proportion of total variation $[\%]$

Among seasons 12.8

Among factories within season 7.2

Among samplers within factory and season 39.9

Among hours within sampler type, factory and season 38.0

Among mediums within hour, sampler type, factory and season 1.3

Among dishes within medium, hour, sampler type, factory and season

Table 4. Descriptive statistics of airborne fungi with respect to considered predictors

\begin{tabular}{|c|c|c|c|c|}
\hline \multirow[t]{2}{*}{ Predictor } & \multicolumn{4}{|c|}{$\begin{array}{l}\text { Airborne fungi } \\
{\left[\mathrm{CFU} / \mathrm{m}^{3}\right]}\end{array}$} \\
\hline & M & SD & back-transformed M & $95 \% \mathrm{CI}$ \\
\hline \multicolumn{5}{|l|}{ Season } \\
\hline spring & 124652 & 211190 & 35193 & $31508-39309$ \\
\hline autumn & 36660 & 67489 & 13865 & $12641-15208$ \\
\hline winter & 20627 & 37043 & 9154 & $8455-9909$ \\
\hline \multicolumn{5}{|l|}{ Sorting facility } \\
\hline A & 34446 & 58582 & 12493 & $11559-13502$ \\
\hline B & 86847 & 181805 & 21710 & 19 928-23 650 \\
\hline \multicolumn{5}{|l|}{ Sampler } \\
\hline filter holder & 9934 & 10342 & 6215 & $5901-6545$ \\
\hline air sampler & 111359 & 180568 & 43642 & $40436-47102$ \\
\hline \multicolumn{5}{|l|}{ Medium } \\
\hline DRBC & 67070 & 148565 & 18984 & $16913-21309$ \\
\hline YGC & 59231 & 132208 & 15542 & $13794-17510$ \\
\hline MEA & 60306 & 137170 & 16110 & $14330-18111$ \\
\hline SDA & 55978 & 131679 & 15476 & $13763-17402$ \\
\hline
\end{tabular}

DRBC - dichloran rose-Bengal chloramphenicol; YGC - yeast extract glucose chloramphenicol; MEA - malt extract agar; SDA - Sabouraud dextrose agar.

SD - standard deviation; back-transformed M - mean on the logarithmic scale (the scale of measurements, where approximation by normal distribution and thus data analysis are possible), which was back-transformed to the original scale; $95 \% \mathrm{CI}-95 \%$ confidence interval of the back-transformed mean (please note the asymmetry of confidence intervals on the original scale, which corresponds to the skewness of the response variable).

Other abbreviations as in Table 1 and 2. 


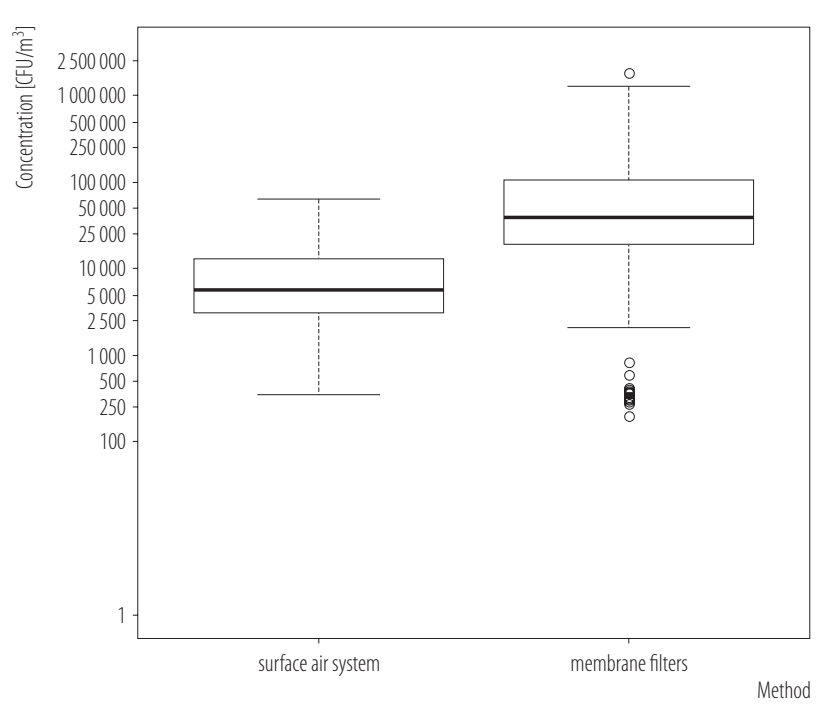

CFU - colony-forming units.

Fig. 1. Concentrations of airborne fungi depending on the type of sampling method

Although the dependence of the detected concentrations of airborne fungi on the type of cultivation medium was statistically significant ( $<<0.001$ ) (Table 2), variability explained by the type of the used medium was negligible when compared to the total $(1.3 \%$ ) (Table 3 ). The highest numbers of detected CFU of airborne fungi within all measurements were detected on DRBC cultivation medium compared to the other cultivation media (SDA, MEA, YGC).

The effect of the type of the waste sorting facility was not significant (Table 2). Variability between waste sorting facilities explained only $7.2 \%$ of the total variability (Table 3).

The SAS method detected more consistently lower concentrations of airborne fungi compared to the MF method. The concentrations ranged $2 \times 10^{2}-1.7 \times 10^{6} \mathrm{CFU} / \mathrm{m}^{3}$ when using the MF method, and $3 \times 10^{2}-6.4 \times 10^{4} \mathrm{CFU} / \mathrm{m}^{3}$ when using the SAS method (Figure 1).

In terms of the comparison of the 2 sampling methods, it is essential that we found no interaction between the type of sampling device and the other predictors (waste sorting facility, sampling time, cultivation medium) (Table 2). Both sampling devices responded equally sensitively to the sampling time and the type of cultivation medium.

\section{DISCUSSION}

Statistically significant differences in the detected concentrations of airborne fungi were found to occur between the measurements during the work shift. Variability in the concentrations of airborne fungi during the work shift could be caused by the quality of sorted waste (contamination by fungi) [9] and the technology of the sorting process (e.g., the open conveyor belt, efficiency of the ventilation system, accumulation of wet waste in sorting facility, organization of work) [2,12]. At the beginning of the work shift, an increasing trend in the concentration of airborne fungi was observed; later on it was constant and then slightly decreased. This trend appeared to be related to the increasing amount of sorted waste from the beginning of the work shift and then decreasing intensity of sorting process towards the end of the work shift associated with the depletion of waste supply for sorting.

As far as cultivation media are concerned, higher numbers of CFU of fungi were detected on DRBC cultivation medium. The surface of the cultivation media SDA, MEA and YGC was often covered by Mucorales fungi that could limit the growth of other fungal species [28] and thus prevent the accurate reading of $\mathrm{CFU}$ number of fungi. On the surface of the cultivation medium DRBC, Mucorales fungi growth was restricted [29] and thus the growth of other fungal species was not limited. For this reason, it seems advisable to detect CFU of airborne fungi from working environments on DRBC cultivation medium.

The results of detected concentrations of airborne fungi show a significant difference between the SAS and the MF method in the detection of airborne fungi. The MF method detected consistently higher concentrations of airborne fungi in comparison to the SAS method. The lower ability of SAS sampler to enumerate airborne 
fungi in comparison to other types of air samplers was also observed in other studies [15,16,30,31]. On the other hand, both sampling methods responded equally sensitively to the fluctuation of airborne fungi concentrations, since otherwise significant interactions of sampler type with other predictors would be detected on such an extensive dataset. This also suggests that a calibration coefficient could be prospectively introduced, which would relate the quantitative measurements of the 2 sampling methods to each other.

Using the MF method, airborne fungi were collected onto the membrane filter from which the particles of the fungi were released into the water. Part of this fluid was spread over the entire surface of the cultivation medium in Petri dish, which allowed CFU of fungi to grow uniformly and to be easily countable [32]. On the other hand, when using the SAS method, the airborne fungi were collected directly on the surface of the cultivation medium in Petri dish. Throughout the sampling, CFU of airborne fungi tended to accumulate at several points on the surface of the cultivation medium. The accumulation of more CFU of fungi at the several points on the surface of the cultivation medium could lead to mutual overgrowing or growth restriction of $\mathrm{CFU}$ of fungi and thus to inaccurate counting of their number [33]. Therefore, it is necessary to use short times and lower flow rates for sampling of airborne fungi when high volume samplers are used in highly contaminated environments. In our study, the amount of air sampled was 501 . This volume of air samples was chosen since higher volumes resulted in overloading.

The results of our measurements show that both sampling methods can be used for monitoring the concentration of airborne fungi in the working environment of waste treatment facilities. The advantage of the SAS method is an easy preparation of the sampling device as well as the subsequent processing of the samples [15]. Apart from Petri dishes with cultivation media, the SAS method does not require any other equipment; therefore this method is suitable for fast indicative determination of the concentration of airborne fungi. The MF method is more timeconsuming regarding the preparation of the sampling device, collection and subsequent processing of samples [32]. The results of sampling show that the MF method provides better information on the concentration of airborne fungi. The MF method is more suitable for a thorough assessment of the contamination of the working environment by airborne fungi in comparison to the SAS method. Therefore, we recommend using the MF method in the context of the unified methodology for the sampling of airborne fungi from working environments of waste treatment facilities.

\section{CONCLUSIONS}

The surface air system method proved to be fully comparable with the membrane filters method. Despite the overall lower absolute concentration of airborne fungi detected by the surface air system method, both sampling methods respond consistently and reliably to the examined factors affecting the concentration of airborne fungi. Therefore they are suitable for airborne fungi monitoring in waste treatment facilities. The surface air system method is suitable for fast indicative determination of the concentration of airborne fungi. However, in the context of the unified methodology for the sampling of airborne fungi from working environments of waste treatment facilities, we recommend using the membrane filters method.

\section{ACKNOWLEDGMENTS}

We thank M.Sc. Pavlina Kolarova for help with language corrections.

\section{REFERENCES}

1. Pahren HR, Clark CS. Microorganisms in municipal solid waste and public health implications. Crit Rev Environ Control. 1987;17(3):187-228, http://dx.doi.org/10.1080/10643388 709388334 . 
2. Park D-U, Ryu S-H, Kim S-B, Yoon C-S. An assessment of dust, endotoxin, and microorganism exposure during waste collection and sorting. J Air Waste Manag Assoc. 2011;61(4): 461-8, http://dx.doi.org/10.3155/1047-3289.61.4.461.

3. Marchand G, Lavoie J, Lazure L. Evaluation of bioaerosol in a municipal solid waste recycling and composting plant. J Air Waste Manag Assoc. 1995;45(10):778-81, http:// dx.doi.org/10.1080/10473289.1995.10467406.

4. Perez HR, Frank AL, Zimmerman NJ. Health effects associated with organic dust exposure during the handling of municipal solid waste. Indoor Built Environ. 2006;15(3):207-12, http://dx.doi.org/10.1177/1420326X06066427.

5. Eker HH, Bayraktarli RY, Işsever H, Ulaş T, Erelel M, Eser AI, et al. Metabolic syndrome in collection and disposal of solid waste sector. Int J Occup Med Environ Health. 2012;25(1):14-21, http://dx.doi.org/10.2478/s13382-012-0004-z.

6. Lehtinen J, Tolvanen O, Nivukoski U, Veijanen A, Hänninen K. Occupational hygiene in terms of volatile organic compounds (VOCs) and bioaerosol at two solid waste management plants in Finland. Waste Manag. 2013;33(4):96473, http://dx.doi.org/10.1016/j.wasman.2012.11.010.

7. Reinthaler FF, Haas D, Feierl G, Schlacher R, PichlerSemmelrock FP, Köck M, et al. Comparative investigations of airborne culturable microorganisms in selected waste treatment facilities and in neighbouring residential areas. Zentralbl Hyg Umweltmed. 1999;202(1):1-17, http://dx.doi. org/10.1016/S0934-8859(99)80046-7.

8. Tolvanen OK, Hänninen KI. Mechanical-biological waste treatment and the associated occupational hygiene in Finland. Waste Manag. 2006;26(10):1119-25, http://dx.doi. org/10.1016/j.wasman.2005.07.020.

9. Würtz H, Breum NO. Exposure to microorganisms during manual sorting of recyclable paper of different quality. Ann Agric Environ Med. 1997;4:129-35.

10. Krajewski JA, Tarkowski S, Cyprowski M, Szarapińska-Kwaszewska J, Dudkiewicz B. Occupational exposure to organics dust associated with municipal waste collection and management. Int J Occup Med Environ Health. 2002;15(3):289-301.
11. Rahkonen P. Airborne contaminants at waste treatment plants. Waste Manag Res. 1992;10(5):411-21, http://dx.doi. org/10.1177/0734242X9201000504.

12. Kiviranta H, Tuomainen A, Reiman M, Laitinen S, Nevalainen A, Liesivuori J. Exposure to airborne microorganisms and volatile organic compounds in different types of waste handling. Ann Agric Environ Med. 1999;6(1):39-44.

13. BS-EN 13098:2001. Workplace atmosphere. Guidelines for measurement of airborne micro-organisms and endotoxin. London: British Standards Institution; 2001.

14. BS-EN 14042:2003. Workplace atmospheres. Guide for the application and use of procedures for the assessment of exposure to chemical and biological agents. London: British Standards Institution; 2003.

15. Yao M, Mainelis G. Effect of physical and biological parameters on enumeration of bioaerosols by portable microbial impactors. J Aerosol Sci. 2006;37(11):1467-83, http://dx.doi. org/10.1016/j.jaerosci.2006.06.005.

16. Yao M, Mainelis G. Analysis of portable impactor performance for enumeration of viable bioaerosols. J Occup Environ Hyg. 2007;4(7):514-24, http://dx.doi.org/10.1080/1545 9620701407388.

17. Burge HA, Solomon WR. Sampling and analysis of biological aerosols. Atmos Environ. 1987;21(2):451-6, http://dx.doi. org/10.1016/0004-6981(87)90026-6.

18. Horner WE, Worthan AG, Morey PR. Air- and dustborne mycoflora in houses free of water damage and fungal growth. Appl Environ Microbiol. 2004;70(11):6394-400, http://dx.doi.org/10.1128/AEM.70.11.6394-6400.2004.

19. Perdelli F, Cristina ML, Sartini M, Spagnolo AM, Dallera $\mathrm{M}$, Ottria $\mathrm{G}$, et al. Fungal contamination in hospital environments. Infect Control Hosp Epidemiol. 2006;27(1):44-7.

20. Blomquist G, Palmgren U, Ström G. Improved techniques for sampling airborne fungal particles in highly contaminated environments. Scand J Work Environ Health. 1984; 10(4):253-8, http://dx.doi.org/10.5271/sjweh.2334.

21. Liu BYH, Lee KW. Efficiency of membrane and nucleopore filters for submicrometer aerosols. Environ Sci 
Technol. 1976;10(4):345-50, http://dx.doi.org/10.1021/es6 $0115 \mathrm{a} 002$.

22. Wang Z, Reponen T, Grinshpun SA, Górny RL, Willeke K. Effect of sampling time and air humidity on the bioefficiency of filter samplers for bioaerosol collection. J Aerosol Sci. 2001;32(5):661-74, http://dx.doi.org/10.1016/S00218502(00)00108-7.

23. Borrego S, Lavin P, Perdomo I, de Saravia SG, Guiamet P. Determination of indoor quality in archives and biodeterioration of the documentary heritage. ISRN Microbiol. 2012;2012:1-10, http://dx.doi.org/10.5402/2012/ 680598.

24. Durand KTH, Muilenberg ML, Burge HA, Seixas NS. Effect of sampling time on the culturability of airborne fungi and bacteria sampled by filtration. Ann Occup Hyg. 2002;46(1):113-8, http://dx.doi.org/10.1093/annhyg/mef007.

25. Crawley MJ. The $\mathrm{R}$ book. Chichester: John Wiley \& Sons, Inc.; 2007.

26. Scheiner SM, Gurevitch J. Design and analysis of ecological experiments. London: Chapman and Hall; 1993. p. 235-66.

27. R Development Core Team [Internet]. Vienna: R Foundation for Statistical Computing; 2013 [cited 2014 June 6]. Available from: http://www.R-project.org.
28. Dijksterhuis J, Samson RA. Zygomycetes. In: de Blackburn CW, editor. Food spoilage microorganisms. Cambridge: Woodhead Publishing Ltd.; 2006. p. 415-36.

29. King AD Jr, Hocking AD, Pitt JI. Dichloran-rose bengal medium for enumeration and isolation of molds from foods. Appl Environ Microbiol. 1979;37(5):959-64, http://dx.doi. org/0099-2240/79/05-0959/06\$02.00/0.

30. Buttner MP, Stetzenbach LD, Monitoring airborne fungal spores in an experimental indoor environment to evaluate sampling methods and the effects on human activity on air sampling. Appl Environ Microbiol. 1993;59(5):219-26.

31. Bellin P, Schillinger J. Comparison of field performance of the Andersen N6 single stage and the SAS sampler for airborne fungal propagules. Indoor Air. 2001;11(1):65-8, http://dx.doi.org/10.1034/j.1600-0668.2001.011001065.x.

32. Martinez KF, Rao C, Burton N. Exposure assessment and analysis for biological agents. Grana. 2004;43(4):193-208, http://dx.doi.org/10.1080/00173130410000794.

33. Eduard W, Heederick D. Methods for quantitative assessment of airborne levels of noninfectious microorganisms in highly contaminated work environments. Am Ind Hyg Assoc J. 1998;59(2):113-27, http://dx.doi. org/10.1080/15428119891010370.

This work is available in Open Access model and licensed under a Creative Commons Attribution-NonCommercial 3.0 Poland License - http://creativecommons.org/ licenses/by-nc/3.0/pl/deed.en. 